\title{
Simulation of Nitrogen Pollution in the Shanxi Reservoir Watershed Based on SWAT Model
}

\author{
A-long Li*, Chen Haitao*, Liu Yuanyuan**, Lin Qiu* and Wang Wenchuan*† \\ *School of Water Conservancy, North China University of Water Resources and Electric Power, Zhengzhou City, \\ Henan Province, 450045, PR China \\ **Henan Huarun Engineering Design Co., Ltd., Zhengzhou City Henan Province, 450045, PR China \\ †Corresponding Author: Wang Wenchuan; liuyuan_hs@sina.com
}

Nat. Env. \& Poll. Tech.
Website: www.neptjournal.com
Received: $13-10-2019$
Revised: $01-11-1019$
Accepted: 11-12-2019
Key Words:
Agricultural non-point
source pollution
SWAT model
Hydrology
Water quality

\begin{abstract}
This study applied the Soil and Water Assessment Tool (SWAT) to the Shanxi Reservoir watershed, a drinking water source in Zhejiang Province, China. The important sources of non-point source pollution (NPS) in Shanxi reservoir watershed are agricultural fertilizer application, domestic sewage and livestock breeding, this brings new challenges to water source management. The simulated runoff and water quality parameters total nitrogen (TN) were compared to those of the observed values in the watershed. The Nash-Suttcliffe efficiency (NSE) was 0.94 for monthly runoff during the calibration period 2007-2010, and 0.84 during the validation period 2011-2012. The model can well satisfy the simulation of runoff. For monthly TN of Sancha water quality monitoring station, the NSE is 0.7 in the calibration period of March 2009 to April 2011, and 0.75 in the verification period of May 2011 to December 2012. For the Jiujiang water quality monitoring station, the model index parameters are slightly lower than Sancha, but it is also very good for water quality simulation. The four parameters of total nitrogen, organic nitrogen (ORGN), nitrate-nitrogen $\left(\mathrm{NO}_{3}-\mathrm{N}\right)$ and ammonia nitrogen $\left(\mathrm{NH}_{4}-\mathrm{N}\right)$ were used to analyse the nitrogen pollution of Shanxi Reservoir watershed. The multi-year monthly average results of nitrogen pollutant loadings show significant differences, with large fluctuations every month. ORGN and $\mathrm{NH}_{4}-\mathrm{N}$ showed a consistent trend, showing a steady growth trend from January to June, peaking in August and continuing to decline in other months, and $\mathrm{NO}_{3}-\mathrm{N}$ peaked in March. The pollution load of TN in Shanxi reservoir watershed ranged from $142.27 \mathrm{~kg} / \mathrm{km}^{2}$ to $725.31 \mathrm{~kg} / \mathrm{km}^{2}$, showing a large spatial difference. The pollution load of the tributary basin is weaker than that of the main stream, which generally shows an increasing trend from upstream to downstream. Overall, the pollutant load is consistent with land use and agricultural production and living conditions, showing typical characteristics of non-point source pollution. Through the establishment of regional nitrogen pollution model and the study of pollutant distribution characteristics, this study puts forward some suggestions for controlling the nitrogen pollution load of the Shanxi Reservoir watershed, optimizes the agricultural planting mode, and intercepts the pollution sources that are not directly discharged into the water body.
\end{abstract}

\section{INTRODUCTION}

For a long time, as an important source of water pollution in river basins, non-point source pollution (NPS) has received more and more attention. Due to the effects of excessive fertilization and pesticide abuse in agricultural production activities, in the absence of management measures, pollutants such as nitrogen and phosphorus will be eutrophicated with runoff into the water bodies of the basin, resulting in environmental hazards such as blooms (Brezonik et al. 1999). In the surface water of Europe, nitrogen and phosphorus pollutants account for more than $50 \%$ of the water entering the basin with agricultural production (Gao \& Zhang 1999). As the key to NPS, nitrogen pollution is more prominent in the management of reservoir water source. In China, more than 15 million tons of nitrogen is lost each year outside the farmland. There are eutrophication problems in $85 \%$ of lakes in China, and the important source of water deterioration is also NPS (Hu et al. 2002). Because NPS has the characteristics of strong randomness, extensiveness, and long latency period, the difficulty of governance is greatly increased $(\mathrm{He}$ et al. 1998).

Water quality models play an important role in NPS research. The mechanistic model can better simulate the basic situation of the basin, such as the case of land surface hydrology, agricultural production (Wang \& Jin 2016). But there are difficulties in calibration parameters. As a large NPS model, SWAT model has a good effect on NPS simulation and has built-in a variety of scenario management measures. 
It is an effective tool for determining the best management measures (BMPs) in the basin (Wang et al. 2003).

The important sources of NPS in drinking water in Shanxi reservoir watershed are agricultural fertilizer application, domestic sewage and livestock breeding, this brings new challenges to water source management. As a primary water source protection site, although the water quality of the main stream in the reservoir area of Shanxi is Class II is according to Chinese Water Quality Standard (GB3838-2002), the water quality of some of the tributaries is not optimistic. The main objective of this study was to: 1) Establishing SWAT model of Shanxi reservoir watershed; 2) Simulation of runoff and nitrogen pollution in the basin; 3) Analyse nitrogen pollution to clarify its temporal and spatial characteristics.

\section{MATERIALS AND METHODS}

\section{Study Area}

The Shanxi Reservoir watershed is located in the south of Zhejiang Province, China, where the dam was completed in 2000 and began to impound. The reservoir as a drinking water source in Wenzhou City, providing drinking water for 7 million people. There are several tributaries within the basin, the tributaries are steep and steep flow, belonging to mountainous rivers, with a total watershed area of $1529 \mathrm{~km}^{2}$. JN, WC, TS three counties are located in the basin. The multi-year average precipitation and temperature are $1876.9 \mathrm{~mm}$ and 19.6 , respectively. The rainfall is concentrated in April and September, accounting for $74.7 \%$ of the whole year. The average number of years of precipitation is 149 days, the minimum year is only 80 days. Between July and September, under the control of the subtropical high ridge, prevailing southerly winds, hot weather, frequent typhoon activities, more thunderstorms and typhoons, causing greater floods. The land use in the catchment area is mainly forest land, grassland, agricultural land and residential land (Mei et al. 2016). Study area location is shown in Fig. 1.

\section{Application of SWAT, Calibration and Validation}

The SWAT (Soil and Water Assessment Tool) model is a distributed, mechanistic hydrological water quality model based on GIS developed by the US Department of Agriculture (USDA). The model can simulate runoff, sediment, nutrients, pesticides, etc.

Arc SWAT 2012 was used as a tool for this study. The collected data was applied to complete SWAT modelling following the principle of first runoff and then pollution loads, and construct, calibration and validation of the SWAT model of Shanxi reservoir watershed. This study uses SWAT-CUP software as a model calibration tool.

SWAT water quality model is established following the order of the first hydrological re-water quality. First, we constructed the monthly scale hydrological model, from 2004 to 2006 as a model warm-up period, data from 2007 to 2010 were used for calibration and data from 2011 to 2012

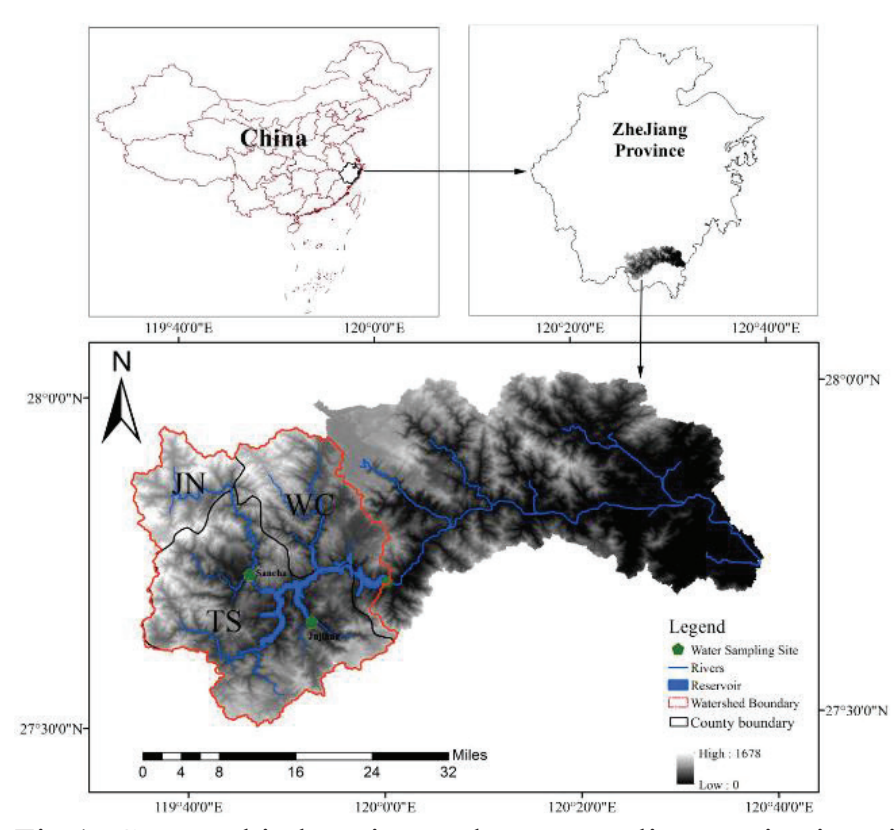

Fig.1: Geographic location and water quality monitoring site of the study area. 
were used for validation. After the runoff simulation meets the accuracy requirements, calibration and verification of the monthly scale water quality model were performed on the data of the two water quality sites in the basin.

In China, often monitored water quality indicators do not include organic nitrogen and nitrate nitrogen. However, we believe that when the runoff calibration is accurate and the water quality is calibrated with $\mathrm{TN}$ as a water quality indicator, the key parameters for the model mechanism and process are accurate. Due to the lack of organic nitrogen and nitrate nitrogen measured data, while the two indicators for the importance of surface water quality assessment, we use accurate SWAT model to output the value of these indicators.

\section{Data Sources}

The DEM data is the $30 \mathrm{~m} \times 30 \mathrm{~m}$ precision data obtained from the Geospatial Data Cloud (http://www.gscloud.cn/). Land use data are based on Landsat TM $30 \mathrm{M}$ remote sensing images in accordance with the national land use classification method of interpretation, the use of ArcGis10.2 reclassified as SWAT land use database. The soil data were derived from the FAO's HWSD Soil Database, converted by the SPAW software to the SWAT required soil database.

There are four rainfall stations in the basin, one hydrological station and two water quality stations as shown in Fig. 1. The daily precipitation data from 1956 to 2012 were provided by the local meteorological department for the construction of the model. The daily flow data for 2007-2012 were provided by the local water conservancy department. Water quality monitoring frequency was once a month, two stations from 2009 to 2012 TN data provided by the local Environmental Protection Agency. Fertilization data were calculated based on the "Statistical Yearbook of Wenzhou" and the field survey, livestock excrement data according to previous studies.

\section{RESULTS AND DISCUSSION}

\section{Calibration and Verification of Runoff and Nitrogen Pollution Simulations}

This study uses the three statistical parameters, Nash-
Sutcliffe efficiency (NSE), the coefficient of determination $\left(\mathrm{R}^{2}\right)$ and Relative error $(\mathrm{Re})$ to indicate the accuracy of the SWAT model simulation results [Eqs. (1), (2) and (3)]. The closer NSE and $\mathrm{R}^{2}$ values are to 1 , the more accurate the model is, and the smaller the absolute value of the Re is, the more accurate the model is (Narsimlu et al. 2015).

$$
\begin{aligned}
N S E & =\frac{\sum_{i=1}^{n}\left(O b s_{i}-\overline{O b s}\right)^{2}-\sum_{i=1}^{n}\left(\operatorname{Sim}_{i}-\overline{S l m}\right)^{2}}{\sum_{i=1}^{n}\left(O b s_{i}-\overline{O b s}\right)^{2}} \\
R^{2} & =\frac{\left[\sum_{i=1}^{n}\left(O b s_{i}-\overline{O b s}\right) \sum_{i=1}^{n}\left(\operatorname{Sim}_{i}-\overline{\operatorname{Sim}}\right)\right]^{2}}{\sum_{i=1}^{n}\left(O b s_{i}-\overline{O b s}\right)^{2} \sum_{i=1}^{n}\left(\operatorname{Sim}_{i}-\overline{\operatorname{Slm}}\right)^{2}} \\
\operatorname{Re} & =\frac{\sum_{i=1}^{n} \operatorname{Sim}_{i}-\sum_{i=1}^{n} O b s_{i}}{\sum_{i=1}^{n} O b s_{i}}
\end{aligned}
$$

Where $O b s_{i}$ is the $\mathrm{i}^{\text {th }}$ observed value, $\overline{O b s}$ is the average observed value over the length of the simulation sequence, $\operatorname{Sim}_{\mathrm{i}}$ is the $\mathrm{i}^{\text {th }}$ simulated value, $\overline{\operatorname{Sim}}$ is the average simulated value over the length of the simulation sequence.

\section{Runoff Calibration and Verification}

The hydrological model was calibrated and validated using continuous runoff data for 2007-2012. The data for the four years from 2007 to 2010 were used as the calibration period, and the verification period was from 2011 to 2012 .

The fit of the measured and simulated values of runoff in the calibrator and verification period is shown in Fig. 2. The model evaluation results are shown in Table 1. It can be seen that the $\mathrm{R}^{2}$ and NSE of the runoff are both above 0.94 during the calibration period, and the verification period value is slightly lower than the calibration period but also above 0.84 . As can be seen from Fig. 2, the simulation of runoff peaks and valleys is very good. The fit between these two simulated values and the measured values is satisfactory, which indicates that the model can well simulate the runoff, which lays a good foundation for the next stage of water quality simulation.

\section{TN Calibration and Verification}

After the calibration and verification of the runoff met the model requirements, we began to calibrate and verify the $\mathrm{TN}$. This study calibrated and validated TN data for two

Table 1: The statistical goodness-of-fit indicators during model evaluation.

\begin{tabular}{|lllllll|}
\hline \multirow{2}{*}{ Type } & Calibration & & \multicolumn{3}{l}{ Verification } \\
\cline { 2 - 7 } & NSE & $\mathrm{R}^{2}$ & $\mathrm{Re}(\%)$ & NSE & $\mathrm{R}^{2}$ & \multicolumn{2}{c|}{$\operatorname{Re}(\%)$} \\
\hline Runoff & 0.94 & 0.95 & -0.07 & 0.84 & 0.85 & 1.85 \\
TN(Sancha) & 0.7 & 0.73 & -13 & 0.75 & 0.86 & -31.3 \\
TN(Jujiang) & 0.57 & 0.73 & -18 & 0.88 & 0.73 & -1.9 \\
\hline
\end{tabular}


water quality monitoring stations, Sancha and Jiujiang, from 2009 to

2012. The period from March 2009 to April 2011 was selected as the calibration period, and the period from May 2011 to December 2012 was the verification period.

The results of the model evaluation are given in Table 1 . It can be seen from the table that the calibration and verification of TN Sancha are better than that of Jiujiang, and both $\mathrm{R}^{2}$ and NSE are close to greater than 0.7 , which is perfect in water quality simulations. It can be seen that the SWAT model of this study can be used to simulate TN of the Shanxi Reservoir watershed.

The fitting of the observed and simulated values of the Jiujiang watershed is shown in Fig. 3. As can be seen from the figure, similar to the results of the runoff simulation, the model has a very high simulation fit for the peak and estimate of the TN. Most studies have shown that the SWAT model is better than the dry season in the simulation of water quality during the simulation of water quality, which is also reflected in this study. Although the dry season observations and the simulated values are not as good as the wet season, it can be seen that the model we built is still a very good simulation of TN in terms of trends, and these deviations are within the acceptable range.

\section{Temporal Distribution of Nitrogen Pollution Load}

This study simulates the monthly average loads of nitrogen pollution in Shanxi Reservoir watershed from 2007 to 2012. The annual variation of the monthly average load of various nitrogen pollutants is shown in Fig. 4. It can be seen that the load of nitrogen pollutants varies greatly and shows obvious changes during the year.

The annual variation trend of organic nitrogen and ammonia nitrogen is very consistent. From January to June, there was a constant growth trend, with a slight decline in July and then peaking in August. Other months continue to decline, which may be because the application of pesticides and fertilizers in the first six months is an accumulation process in the basin. By August, the study area is affected by extreme weather such as heavy rain and even typhoon, which

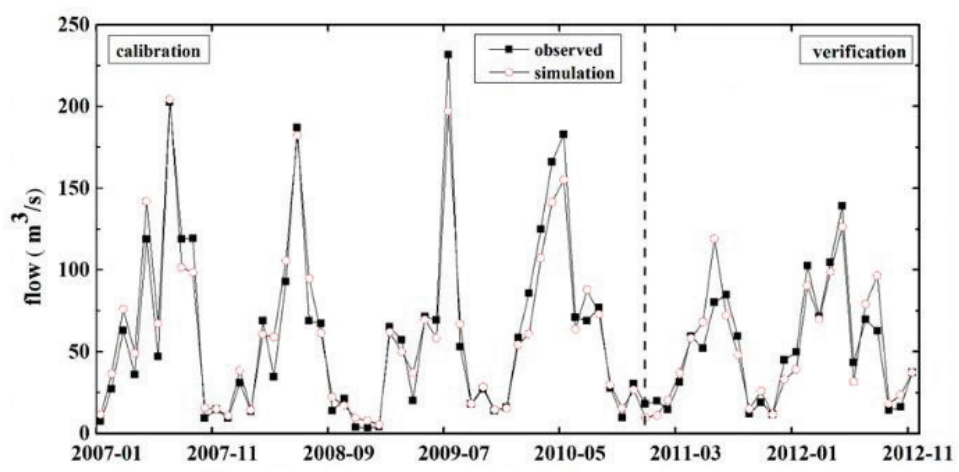

Fig. 2: Observed and simulated values of runoff during the calibration period and verification period 2007-2012.

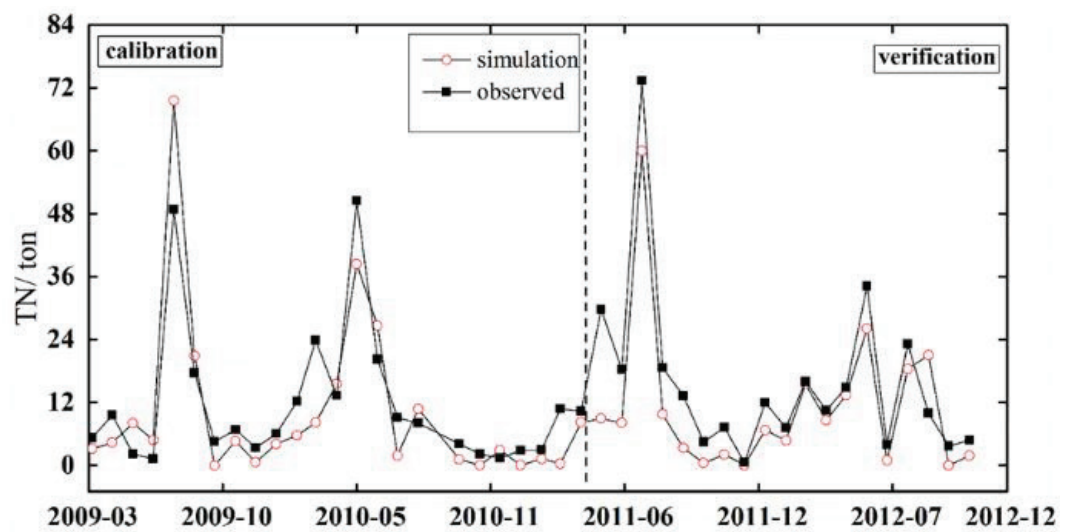

Fig. 3: Observed and simulated values of TN during the calibration period and verification period 2009-2012. 
indicates that the pollutant load and runoff are closely related. In the dry season, due to the decrease of precipitation, the runoff is reduced, which greatly reduces the amount of loss (Joongdae et al. 2012). However, the load of the two has a huge difference, which may have a major relationship with the type of land use in the basin.

Unlike the peaks of organic nitrogen and ammonia nitrogen in August, the nitrate-nitrogen load reached a peak in March, which may be related to the agricultural farming method in the basin. During this period, rice cultivation began to be planted in the basin, and the application of nitrogen fertilizer may bring huge nitrate-nitrogen loads.

\section{Spatial Distribution of Nitrogen Pollution Load}

Table 2 lists the annual average area loss of nitrogen pollutants from 2007 to 2012. It can be seen that the main contribution of total nitrogen in the Shanxi Reservoir watershed is organic nitrogen, followed by nitrate nitrogen and ammonia nitrogen. The spatial distribution of nitrogen pollutants in each sub-basin of Shanxi Reservoir watershed is shown in Fig. 5.

As can be seen from Fig. 5, the areas with serious nitrogen pollutants are mainly concentrated in the two counties of TS and WC, while the pollutant load in JN is much smaller. This is mainly because the two counties in TS and WC have more human activities and busy agricultural production, while in JN many mountainous forests, human activities are relatively small, and the local agricultural production is not particularly developed.

The average annual total nitrogen loss in the Shanxi Reservoir basin is 438 tons, and the loss per unit area of each sub-basin is from 142.27 to $725.31 \mathrm{~kg} / \mathrm{km}^{2}$. The areas with the most serious total nitrogen pollution load per unit area are sub-basins of 10, 29 and 12, and the annual total nitrogen loss is $725.3 \mathrm{~kg} / \mathrm{km}^{2}, 636.4 \mathrm{~kg} / \mathrm{km}^{2}$ and $588.2 \mathrm{~kg} /$ $\mathrm{km}^{2}$, respectively. It can be seen from Fig. 5 that the spatial distribution of organic nitrogen and total nitrogen is consistent. Sub-basin 10 is dominated by livestock and poultry farming, and the discharge of animal manure and domestic sewage is the main reason for the large organic nitrogen content in the region. Sub-basin 29 is the seat of the county government of TS County, and the intense human activities have brought about a large loss of organic nitrogen. The sub-basin 12 is the same as the sub-basin 10 .

The area with the highest nitrate-nitrogen load is located in sub-basin 25 , reaching $6.3 \mathrm{~kg} / \mathrm{km}^{2}$. This sub-basin is located in the agricultural planting area of TS. The land-use type and unreasonable agricultural planting methods are the main reasons for the high nitrate content in this area. The ammonia nitrogen load in the 17 and 18 sub-basins is the largest, reaching $9.26 \mathrm{~kg} / \mathrm{km}^{2}, 9.21 \mathrm{~kg} / \mathrm{km}^{2}$, respectively. The two sub-basins are located near the exit of the basin. The town of Shanxi is located in it. The intense human activities may be the main reason for the large ammonia nitrogen load in this area.

It can also be seen from the figure that the pollution load of the tributary basin is weaker than that of the main stream, and at the same time it generally shows an increasing trend from the upstream to the downstream. Overall, pollutant loading is consistent with land use and agricultural production and living conditions, presenting typical characteristics of NPS (Chen et al. 2016).

\section{CONCLUSIONS}

In the Shanxi Reservoir watershed, this study established a SWAT-based NPS model. The model shows a very good simulation of nitrogen pollution by calibration and verification of runoff and TN. The study also found that the pollution load of

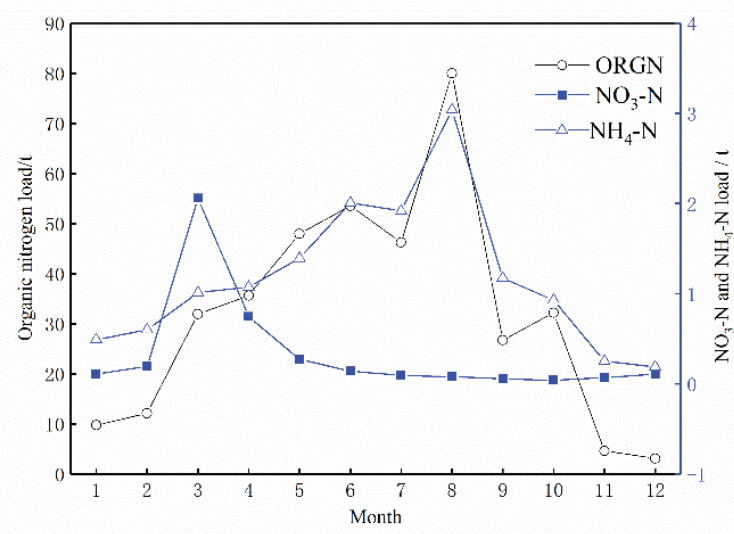

Fig. 4: Monthly average change in nitrogen pollution load. 
Table 2: Annual average nitrogen pollutant loss in each sub-basin.

\begin{tabular}{|c|c|c|c|c|}
\hline Sub-basin & $\begin{array}{l}\text { ORGN } \\
\left(\mathrm{kg} / \mathrm{km}^{2}\right)\end{array}$ & $\begin{array}{l}\mathrm{NO}_{3}-\mathrm{N} \\
\left(\mathrm{kg} / \mathrm{km}^{2}\right)\end{array}$ & $\begin{array}{l}\mathrm{NH}_{4}-\mathrm{N} \\
\left(\mathrm{kg} / \mathrm{km}^{2}\right)\end{array}$ & $\begin{array}{l}\text { TN } \\
\left(\mathrm{kg} / \mathrm{km}^{2}\right)\end{array}$ \\
\hline 1 & 145.15 & 0.99 & 0.69 & 146.83 \\
\hline 2 & 247.97 & 1.34 & 0.51 & 249.83 \\
\hline 3 & 320.49 & 2.04 & 0.11 & 322.65 \\
\hline 4 & 272.85 & 1.68 & 2.49 & 277.02 \\
\hline 5 & 184.01 & 0.63 & 0.49 & 185.13 \\
\hline 6 & 139.58 & 0.97 & 1.71 & 142.27 \\
\hline 7 & 235.82 & 1.73 & 2.81 & 240.37 \\
\hline 8 & 508.21 & 0.98 & 1.64 & 510.84 \\
\hline 9 & 231.99 & 1.74 & 2.86 & 236.58 \\
\hline 10 & 723.37 & 0.44 & 1.49 & 725.31 \\
\hline 11 & 270.21 & 1.12 & 0.60 & 271.94 \\
\hline 12 & 584.83 & 0.68 & 2.74 & 588.23 \\
\hline 13 & 228.34 & 3.94 & 4.17 & 236.44 \\
\hline 14 & 249.06 & 2.77 & 8.21 & 260.08 \\
\hline 15 & 282.03 & 1.50 & 1.10 & 284.63 \\
\hline 16 & 235.98 & 2.74 & 1.64 & 240.35 \\
\hline 17 & 247.76 & 2.66 & 9.26 & 259.73 \\
\hline 18 & 251.02 & 2.59 & 9.21 & 262.87 \\
\hline 19 & 260.01 & 2.48 & 7.07 & 269.56 \\
\hline 20 & 182.36 & 0.96 & 2.17 & 185.50 \\
\hline 21 & 213.06 & 2.98 & 1.84 & 217.86 \\
\hline 22 & 357.48 & 0.50 & 3.08 & 361.06 \\
\hline 23 & 254.01 & 2.99 & 2.73 & 259.75 \\
\hline 24 & 240.72 & 2.76 & 5.49 & 248.99 \\
\hline 25 & 258.11 & 6.30 & 0.51 & 264.90 \\
\hline 26 & 413.43 & 1.28 & 7.25 & 421.95 \\
\hline 27 & 522.05 & 1.66 & 2.51 & 526.24 \\
\hline 28 & 343.82 & 0.86 & 0.56 & 345.24 \\
\hline 29 & 633.34 & 2.52 & 0.52 & 636.38 \\
\hline 30 & 542.62 & 0.63 & 3.79 & 547.05 \\
\hline 31 & 278.35 & 2.44 & 5.70 & 286.50 \\
\hline 32 & 350.52 & 2.02 & 3.36 & 355.90 \\
\hline 33 & 541.91 & 1.63 & 2.35 & 545.86 \\
\hline 34 & 348.47 & 1.83 & 0.78 & 351.05 \\
\hline 35 & 340.28 & 1.74 & 1.55 & 343.58 \\
\hline 36 & 309.23 & 1.15 & 0.75 & 311.13 \\
\hline 37 & 473.01 & 2.51 & 3.81 & 479.35 \\
\hline
\end{tabular}




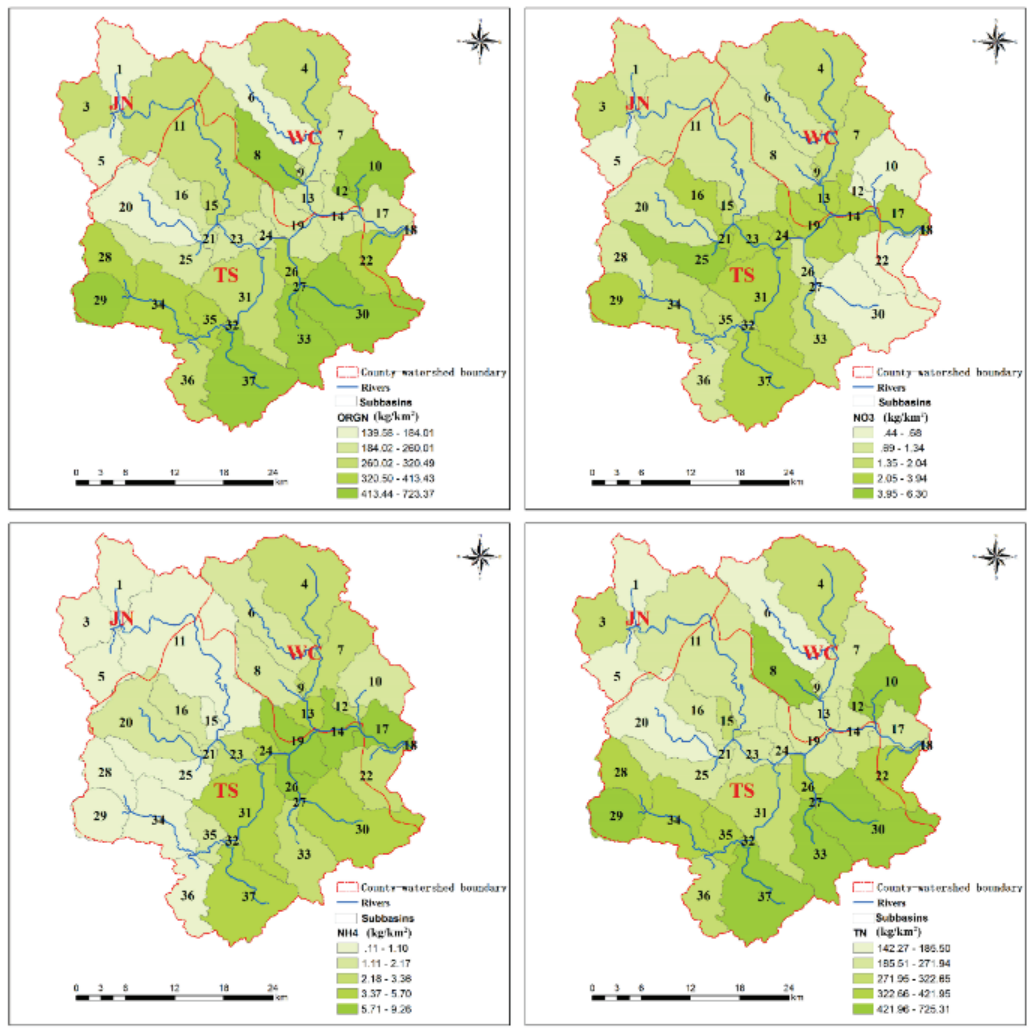

Fig. 5: The spatial distribution of nitrogen pollutants in each sub-basin.

organic nitrogen and ammonia nitrogen in the study area is closely related to precipitation runoff. The nitrate-nitrogen pollution load is related to the agricultural planting method. The study of the spatial distribution of pollutant load found that the nitrogen pollution in the region showed typical non-point source pollution characteristics. The areas with heavy organic nitrogen and ammonia nitrogen load are mainly located in areas where human activities are intense, while the areas with heavy nitrate-nitrogen load are mainly located in agricultural planting areas. The pollutant load in the tributary area is less than the main steam. Through the establishment of regional nitrogen pollution model and the study of pollutant distribution characteristics, this study puts forward some suggestions for controlling the nitrogen pollution load of the Shanxi Reservoir watershed, optimizes the agricultural planting mode, and intercepts the pollution sources that are not directly discharged into the water body.

In the next phase of the study, SWAT's built-in scenario management module can be applied to set up different management measures for heavily polluted areas, study the reduction of pollutants, and provide decision-making basis for local management departments.

\section{ACKNOWLEDGEMENTS}

This research was supported by the Key Scientific and Technological Research Projects in Henan Province (Grants No. 192102110199).

\section{REFERENCES}

Brezonik, P.L. Easter, K. W. Hatch, L. Mulla, D. and Perry, J. 1999. Management of diffuse pollution in agricultural watersheds: Lessons from the Minnesota River basin. J. Water Science \& Technology, 39(12): 323-330.

Chen, L., Wang, G., Zhong, Y. C. and Shen, Z. Y. 2016. Evaluating the impacts of soil data on hydrological and nonpoint source pollution prediction. J. Science of the Total Environment, 563-564: 19-28.

Gao, C. and Zhang, T. L. 1999. Management measures for controlling agricultural nutrient polluted water environment in European countries. J. Journal of Ecology and Rural Environment, 15(2): 50-53.

He, C. S., Fu, B.J. and Chen, L. X. 1998. Management and control of nonpoint source pollution. J. Environmental Science, (5): 87-91.

Hu, X. T., Chen, J. N. and Zhang, T. Z. 2002. A study on non-point source pollution models. J. Chinese Journal of Environmental Science, 23(3): 124.

Joongdae, C., Minhwan, S., Jiseong, Y. and Jeongryeol, J. 2012. Effect of rice straw mulch on runoff and NPS pollution discharges from a vegetable field. J. Soil \& Water Engineering International Conference of Agricultural Engineering-cigr-ageng: Agriculture \& Engineering for A Healthier Life, 2012. 
Mei, K., Shang, X., Wang, Z. F., Huang, S. H., Dong, X. and Huang, H. 2016. Study on the influence of land use on nitrogen memory effect in watershed. J. Journal of Environmental Science, 36(10): 3856-3863.

Narsimlu, B., Gosain, A. K., Chahar, B. R., Singh, S. K. and Srivastava, P. K. 2015. SWAT model calibration and uncertainty analysis for streamflow prediction in the Kunwari River Basin, India, using sequential uncer- tainty fitting. J. Environmental Processes, 2(1): 79-95.

Wang, X. C. and Jin, M. J. 2016. Progress in the application of distributed hydrological model SWAT in non-point source pollution research. J. Journal of Agricultural Science Yanbian University, 38(3): 271-276.

Wang, Z. G. and Liu, C. M. 2003. The theory of SWAT model and its application in Heihe Basin. J. Progress in Geography, 22(1). 